\title{
Acidente motociclístico com reabilitação precoce: relato de caso
}

Motorcycle accident with early rehabilitation: case report

Accidente motociclista con rehabilitación precoz: reporte de caso

\author{
Talita Costa BARBOSA ${ }^{1}$ \\ Gustavo Faleiro BARBOSA ${ }^{1}$ \\ Amanda Oliva SPAZIANI ${ }^{1}$ \\ Raissa Silva FROTA ${ }^{2}$ \\ Luis Carlos SPAZIANI ${ }^{3}$
}

Pedro Augusto Izidoro PEREIRA ${ }^{1}$

Patrícia Michelassi Carrinho AURELIANO ${ }^{4}$

Flávio Henrique Nuevo Benez dos SANTOS 5

Curso de Medicina, Universidade Brasil, Campus Fernandópolis, 15600-000 Fernandópolis-SP, Brasil

${ }^{2}$ Curso de Medicina, Universidade de Rio Verde, campus Goianésia, UniRV, 76380-000 Goianésia-GO, Brasil

${ }^{3}$ Engenheiro de Materiais, Universidade Federal de São Carlos(UFSCAR) Mestre em Economia do Meio Ambiente (UNB)

${ }^{4}$ Fisioterapeuta, Faculdades Integradas de Santa Fé do Sul ; Mestre em Processos de Avaliação e Intervenção em Fisioterapia (UFSCAR),

Doutora em Engenharia Biomédica (Universidade Brasil)

${ }^{5}$ Médico, Universidade São Francisco (USF); Especialista em Ortopedia e Traumatologia, Universidade São Francisco (USF); Especialista em Medicina Física e Reabilitação, Rede Lucy Montoro; Mestre em Ciências da Saúde, Universidade São Francisco (USF)

\section{Resumo}

Nos acidentes de trânsito os motociclistas são os mais prejudicados, pois são os mais suscetíveis ao mesmo. Após a injúria, geralmente se faz a reabilitação multiprofissional. Paciente, sexo masculino, 19 anos, vítima de acidente motociclístico apresentando dor e deformidade em membro inferior direito, com fratura e exposição óssea de fêmur, fratura exposta de patela, sendo ambas classificadas como grau 3-A, e tíbia com laceração do ligamento patelar grau 2, além de perda de massa muscular e óssea. Foi levado ao centro cirúrgico para lavagem e desbridamento, osteossíntese interna e reparação ligamentar. De alta hospitalar, foi encaminhado para reabilitação, onde se iniciou fisioterapia para ganho de arco de movimento, fortalecimento muscular, propriocepção e treino de marcha com carga parcial de $10 \%$ do peso corporal. Após 16 semanas, o mesmo apresentava consolidação das fraturas, arco de movimento de 180 graus de extensão e 100 graus de flexão do joelho. Depois, permaneceu no condicionamento físico por 12 semanas para ganho de força e massa muscular até alta do serviço. É necessária maior atenção pós-acidente devido sua repercussão na vida da vítima, uma vez que propiciar uma reabilitação precoce evidenciou uma recuperação acelerada das pessoas com comprometimento de suas capacidades funcionais.

Descritores: Terapia por Exercício; Fraturas Ósseas; Traumatologia.

\section{Abstract}

Motorcyclists are the most harmed people in traffic accidents due to their susceptibility. After the injury, multiprofessional rehabilitation is usually done. A 19-year-old men patient, motorcycle accident victim presenting pain and right lower limb deformity, with fracture and bone exposure of the femur, open fracture of the patella, both grade 3-A, and tibia with patellar ligament rupture grade 2 , as well as muscle and bone mass loss. He was taken to the operating room to flushing and debridement, internal osteosynthesis and ligament repair. A rehabilitation post hospital discharge started with physiotherapy to improve range of motion (ROM), muscle strengthening, proprioception and gait training with partial body weight support (10\%). After 16 weeks, he was presenting fractures healing, ROM of 180 degrees and 100 degrees of knee flexion. Then, he stayed in physical conditioning for 12 weeks to gain strength and muscle mass until discharge. It is necessary a major postaccident attention because of its impact on victim's life, since early rehabilitation interventions sped up the recovery of impaired functional capacity people.

Descriptors: Exercise Therapy; Fractures, Bone; Traumatology.

\section{Resumen}

En los accidentes de tránsito los motociclistas son los que más afectados, pues son los más susceptibles. Despúes del accidente generalmente es realizada la rehabilitación multiprofesional. Sexo masculino, 19 años, víctima de accidente motociclístico que presenta dolor y deformidad en miembro inferior derecho. Presentaba dolor, deformidad de muslo, rodilla, pierna derecha con fractura y exposición ósea de femur, fractura expuesta de rótula y tibia con laceración del ligamento patelar y pérdida de masa muscular y ósea. La fractura expuesta de femur y rótula fue clasificada como grado 3-A, y la de tibia grado 2. Paciente fue encaminado al centro quirúrgico para lavado y desbridamiento, osteosíntesis interna y reparación ligamentar. Despúes del alta hospitalaria fue encaminado para rehabilitación donde empezó fisioterapia para gano de arco de movimiento, fortalecimiento muscular, propiocepción y entrenamiento de marcha con carga parcial de $10 \%$ del peso corporal. Después de 16 semanas, presentaba consolidación de las fracturas, arco de movimiento de 180 grados de extensión y 100 grados de flexión de rodilla. Fue encaminado para el acondicionamiento físico donde permaneció por 12 semanas para gano de fuerza y masa muscular hasta el alta. Es necesario más atención posaccidente devido a su repercusión en la vida de la víctima. Propiciar una rehabiltiación precoce evidenció una recuperación accelerada de las personas con deterioro de sus capacidades funcionales.

Descriptores: Terapia por Ejercicio; Fracturas Óseas; Traumatología.

\section{INTRODUÇÃO}

Nos acidentes de trânsito os motociclistas são os mais prejudicados, já que são mais suscetíveis a lesões. Estudiosos dedicados ao tema, em estudos recentes, apontam que as causas são multifatoriais, destacando-se os procedimentos de risco dos próprios condutores, a exemplo de pilotar no chamado "corredor das vias", e o consumo de álcool. Se o risco de morte em uma colisão de automóvel já é significativo, a depender das circunstâncias do acidente, sobre uma motocicleta essas chances aumentam em 20 vezes. Esse percentual é aumentado em 60 vezes nos casos em que o piloto não se utiliza de capacete, item de segurança obrigatório em aderência à legislação atual ${ }^{1}$.

A morbimortalidade eleva-se em acidentes automobilísticos que envolvem motociclistas, principalmente devido à fragilidade do tipo de transporte e ausência de equipamentos de segurança presentes em carros, e que não estão disponíveis em motocicletas ${ }^{2}$.

Após o acidente se faz, geralmente, necessário a reabilitação, visto que, normalmente, os envolvidos apresentarem lesões significativas e, muitas vezes, de difícil recuperação. A terapêutica é 
um processo educacional que visa reduzir a incapacidade gerada pela lesão e é realizada por uma equipe multiprofissional ${ }^{3}$.

A reabilitação, mesmo sendo um processo demorado, oportuniza a capacidade de melhorar e transformar vidas, permitindo a pessoa acidentada a ter plena capacidade de realizar todas as funções que realizava antes da ocorrência do evento. Dados atuais de diferentes estudos comprovam que, quanto mais cedo o paciente lesionado por acidentes motociclísticos for submetido ao processo terapêutico de reabilitação, melhores os resultados apresentados. Como consequência, menor será o ônus para o sistema de saúde pública, com menor ocupação de leitos, menor tempo de internação e utilização significativamente menor de medicamentos no tratamento ${ }^{2}$.

Considerando os fatores destacados, este estudo objetiva relatar um caso de acidente automobilístico envolvendo motocicletas e a reabilitação do motoqueiro, preferencialmente precoce e buscar no apoio na literatura de dados relacionados ao caso clínico.

\section{CASO CLÍNICO}

idade, vaciente do sexo masculino, 19 anos de apresentando dor e deformidade em membro inferior direito. Apresentou-se em regular estado geral, hipocorado $(++/ 4+)$. A frequência cardíaca correspondia a 120 batimentos por minuto e a pressão arterial era 90/60 $\mathrm{mmHg}$. Respondia com dor a palpação superficial e profunda, deformidade de coxa, de joelho, de perna direita com fratura e exposição óssea de fêmur, fratura exposta de patela e tíbia com laceração do ligamento patelar e perda de massa muscular e óssea. A fratura exposta de fêmur direito e da paleta foi classificada como grau 3-A e a de tíbia direita, grau 2. O paciente foi encaminhado ao centro cirúrgico onde foi realizada lavagem e desbridamento cirúrgico com 8 litros de soro fisiológico de $0,9 \%$, osteossíntese interna e reparação ligamentar. Recebida alta hospitalar o paciente foi encaminhado ao serviço de reabilitação, iniciando-se, assim, fisioterapia para ganho de arco de movimento, fortalecimento muscular, propriocepção e treino de marcha com carga parcial de $10 \%$ do peso corporal.

Decorridas 16 semanas, o paciente apresentava consolidação das fraturas, arco de movimento de 180 graus de extensão e 100 graus de flexão do joelho. Dessa forma, o paciente foi encaminhado para o condicionamento físico, permanecendo por 12 semanas com o intuito de adquirir força e massa muscular. Concluído esse cíclico, o paciente teve alta do tratamento da reabilitação, retornando às suas atividades habituais e rotineiras.

\section{DISCUSSÃO}

$\mathrm{O}$ uso da motocicleta como meio alternativo de transporte tem aumentado significativamente nos últimos anos, e, como consequência, houve, também, o aumento de ocorrências de trânsito envolvendo esse tipo de veículo de transporte, tornando-o importante instrumento de causa de lesões, incapacidade física e, até mesmo, morte. Em função de valores e necessidades, a motocicleta é usada como meio de transporte ao trabalho ou como ferramenta de trabalho, o que pode levar o usuário a períodos longos de exposição ao trânsito, ocasionando fadiga, cansaço, diminuição dos reflexos e da capacidade de concentração ${ }^{4}$.

Algumas razões que maximizam riscos de ocorrências de acidentes com os motoqueiros são: a falta de atenção ou negligência dos condutores de outros veículos normalmente de maior porte que as motocicletas; a complexidade de manejo das motocicletas; reflexos diminuídos dos motociclistas em consequência do uso de álcool, drogas, medicamentos, excesso de tempo de pilotagem; motociclistas que não possuem o devido treinamento além do excesso de confiança e atração dos próprios pelo risco de pilotagem agressiva ${ }^{4}$.

$\mathrm{O}$ atendimento inicial com avaliação primária, estabilização e transporte da vítima até um centro de melhor referência para dar continuidade ao serviço de emergência minimiza a ocorrência de lesões decorrentes de um atendimento ineficiente no local. Além disso, gera informações para o aprimoramento de políticas públicas mais efetivas na prevenção de doenças e agravos, educação, proteção e recuperação da saúde e reabilitação das pessoas ${ }^{5}$.

Pesquisas mostraram que os seguimentos mais afetados nos acidentes envolvendo motociclistas são os membros inferiores, superiores e cabeça. Tais estudos confirmam a presença frequente, e em conjunto, desses traumas; porém, os membros inferiores são as maiores causas de morbidade, visto serem regiões mais desprotegidas, fato evidenciado nos achados do caso clínico objeto desse estudo. A alta letalidade relaciona-se a traumatismos cranioencefálicos, previsíveis pela utilização do capacete $^{5}$.

O uso do capacete é requisito essencial e obrigatório para condução de motocicletas, mas fica evidente em estudos o elevado percentual de condutores que não o utilizavam no momento do acidente, apesar dessa negligência ser uma infração gravíssima, segundo o artigo 244 do Código Nacional de Trânsito (Lei n. 9.503, de 23 de setembro de 1997), tendo como penalidade multa e suspensão do direito de pilotar motos ${ }^{5}$.

O paciente acidentado por moto costuma ser jovem, do sexo masculino, com baixa escolaridade, portador de carteira há menos de cinco anos, com renda salarial média inferior a mil reais por mês e usuário de moto com baixa cilindrada. ${ }^{6}$ A reabilitação é um ponto de fundamental importância para se 
alcançar resultados funcionais desejados. Considerase, como variáveis importantes da evolução deste processo: dor, estabilidade articular, lesões associadas, força muscular, atividades funcionais, sintomas específicos, retorno à atividade, e tempo de reabilitação ${ }^{7}$. Propiciar uma reabilitação precoce evidenciou, neste caso, corroborado com outros estudos encontrados na literatura, uma recuperação acelerada das pessoas que tiveram comprometidas suas capacidades funcionais em acidentes de trânsito envolvendo motociclistas.

Nesse sentido, é necessária maior atenção pós-acidente devido sua repercussão na vida da vítima. $\mathrm{O}$ aceso facilitado ao serviço de reabilitação é importante na saúde pública, não permite que o paciente sofra desnecessariamente e potencializa o bom prognóstico na evolução do caso ${ }^{8}$.

$\mathrm{O}$ entendimento dos fatores relacionados aos acidentes motociclísticos tem demonstrado a necessidade de recursos para sua prevenção, com atuação conforme os fatores de risco específicos da população alvo9. Conhecer esse cenário e a problemática é de fundamental importância, seja no atendimento pré-hospitalar, intra-hospitalar e póshospitalar, nos cuidados de enfermagem prestados às vítimas, nas salas de emergência dos centros de trauma, na atenção básica, promovendo discussão e educação para o trânsito junto à população, principalmente entre os motociclistas em potencial.

\section{REFERÊNCIAS}

1. Em Discussão. $O$ ponto focal no aumento das mortes. Em Discussão. 2012;(13):16-57. Disponível em: http://www.senado.gov.br/ NOTICIAS/JORNAL/EMDISCUSSAO/upload/2 01204\%20-\%20novembro/pdf/em\%20discuss \%C3\%A3o!_novembro_2012_internet.pdf

2. Ganne N, Martinez AT, Rodrigues C, Delgado MHC, Souza FA. Estudo sobre acidentes de trânsito envolvendo motocicletas, ocorridos no Município de Corumbá, Estado de Mato Grosso do Sul, Brasil, no ano 2010. Rev Pan-Amaz Saúde. 2013;4(1):15-22.

3. Jácomo AAE, Garcia ACF. Análise dos acidentes motociclísticos no Centro de Reabilitação e Readaptação Dr. Henrique Santillo (CRER). Acta Fisiátr. 2011;18(3):124-29.

4. Oliveira NLB, Sousa RMC. Risco de lesões em motociclistas nas ocorrências de trânsito. Rev Esc Enferm USP. 2012;46(5):1133-40.

5. Rezende Neta DS, Alves AKS, Leão GM, Araújo AA. Perfil das ocorrências de politrauma em condutores motociclísticos atendidos pelo SAMU de Teresina-PI. Rev Bras Enferm. 2012; 65(6):936-41.

6. Zabeu JL A, Zovico JRR, Pereira Júnior WN, Tucci Neto PF. Perfil de vítima de acidente motociclístico na emergência de um hospital universitário. Rev Bras Ortop. 2013;48(3):242-45.

7. Pereira M, Vieira NS, Brandão ER, Ruaro JA, Grignet RJ, Fréz AR. Tratamento fisioterapêutico após reconstrução do ligamento cruzado anterior. Acta Ortop Bras. 2012;20(6):372-75.

8. Stucki G, Stier-Jarmer M, Grill E, Melvin J. Rationale and principles of early rehabilitation care after an acute injury or illness. Disabil Rehabil. 2005;27(7-8):353-59.

9. Tavares FL, Coelho MJ, Leite FMC. Homens e acidentes motociclísticos: caracterização dos acidentes a partir do atendimento pré-hospitalar. Esc Anna Nery. 2014;18(4):656-61.

\section{CONFLITO DE INTERESSES}

Os autores declaram não haver conflitos de interesse.

\section{AUTOR PARA CORRESPONDENCIA}

\section{Talita Costa Barbosa}

talitacostabarbosa@gmail.com

Submetido em 18/06/2019

Aceito em 07/11/2019 